\title{
Plasma Adenosine Levels in Peri-Menopausal Women Having Frequent Hot Flushes
}

\author{
Shunji Suzuki, MD; Tsutomu Takeuchi, MD
}

\begin{abstract}
Background The effect of hormone replacement therapy (HRT) on plasma adenosine levels was investigated in climacteric women experiencing hot flushes.

Methods and Results Plasma adenosine levels were measured in 13 peri-menopausal women with frequent hot flushes ( $>5$ per day) before and 3-4 months after initiating HRT. Thirteen healthy pre-menopausal, 9 perimenopausal women with few hot flushes ( $<1$ or 2 per day) and 10 healthy postmenopausal women were enrolled as controls. The average plasma adenosine level in the peri-menopausal women was $0.20 \pm 0.09 \mu \mathrm{mol} / \mathrm{L}$, which was significantly higher than in the pre-menopausal $(0.12 \pm 0.07 \mu \mathrm{mol} / \mathrm{L}, \mathrm{p}<0.05)$, peri-menopausal with few hot flushes $(0.10 \pm 0.09 \mu \mathrm{mol} / \mathrm{L}, \mathrm{p}<0.05)$ and postmenopausal women $(0.13 \pm 0.06 \mu \mathrm{mol} / \mathrm{L}, \mathrm{p}<0.05)$. Both the increased adenosine level and the hot flushes were decreased by HRT (plasma adenosine: $0.13 \pm 0.06 \mu \mathrm{mol} / \mathrm{L}$ ).

Conclusions Increased plasma adenosine in peri-menopausal women may be associated with frequent hot flushes. (Circ J 2005; 69: 1540-1542)
\end{abstract}

Key Words: Adenosine; Estrogen; Hormone replacement therapy; Hot flushes; Peri-menopausal women

M enopause is associated with an increased risk of cardiovascular disease. Several protective actions of estrogen, including peripheral vasodilation, have been described, 1,2 but the mechanisms underlying these effects remain unclear. Increased adrenergic activity and/or higher cardiovascular responsiveness have been reported to occur in peri- and postmenopausal women, 3,4 although not all authors concur with this finding5 For example, Komesaroff et al observed that estrogen supplementation attenuates blood pressure, glucocorticoid, and catecholamine responses to psychological stress in perimenopausal women6 Hot flushes, one of the most common and earlier symptoms of the climacteric (peri-menopausal) syndrome, are characteristic sudden sensations of intense heat with sweating and flushing, but these episodes typically disappear after $1-5$ years in the vast majority of postmenopausal women? Hot flushes have also been reported to be associated with endocrine changes such as increased catecholamine production in the brain?

Adenosine is a vasoactive purine metabolite that is a potent vasodilator in many organs and a metabolic regulator in the cardiovascular system? In earlier studies of patients with chronic heart failure, elevation of plasma adenosine levels was observed and thought to attenuate the cardiovascular effect of norepinephrine-13 Although some earlier studies have denied the effect of estrogen on adenosine as a primary endothelium-independent vasodilator in postmenopausal women ${ }^{14,15}$ changes in plasma adenosine levels in peri-menopausal women with hot flushes have not previously been examined. In this study, we measured plasma adenosine levels and observed the effect of hormone (estro-

(Received May 30, 2005; revised manuscript received September 12, 2005; accepted September 16, 2005)

Department of Obstetrics and Gynecology, Tokyo Rinkai Hospital, Tokyo, Japan

Mailing address: Shunji Suzuki, MD, Department of Obstetrics and Gynecology, Tokyo Rinkai Hospital, 1-4-2 Rinkai-cho, Edogawa-ku, Tokyo 134-0086, Japan. E-mail: czg83542@mopera.ne.jp gen) replacement therapy (HRT) on the adenosine level in peri-menopausal women experiencing hot flushes.

\section{Methods}

In accordance with hospital policies on human research, informed consent was obtained from all subjects prior to the study. Between April 2002 and March 2005, we obtained $8.0 \mathrm{ml}$ samples of blood from 32 outpatients whose chief compliant was hot flushes and 29 healthy female volunteers who came to the hospital for cancer screening. Using these samples, we measured serum estradiol (E2) and folliculestimulating hormone (FSH) levels by radioimmunoassay with commercially available kits according to the manufacturer's instructions. Peri-menopause was defined as the presence of hot flushes with serum E2 $<30 \mathrm{pg} / \mathrm{ml}$ and FSH $\geq 40 \mathrm{mIU} / \mathrm{ml}$. In this study, peri-menopausal women with hot flushes were divided into 2 groups: $>5$ times per day was defined as frequent hot flushes $(n=13) ;<1$ or 2 times per day was defined as few hot flushes $(n=9)$. Thirteen perimenopausal patients with frequent hot flushes (average age, 48.1 \pm 2.0 (range: 44-52) years old, frequent hot flushes group) received 28-day cycle HRT: oral conjugated equine estrogens $0.625 \mathrm{mg} /$ day (Premarin) from days 5 to 18 , a combination of Premarin with $2.5 \mathrm{mg} /$ day continuous medroxyprogesterone acetate (Provera) from days 19 to 25 then a 7-day drug withdrawal. Before HRT and then 3-4 months after the start of HRT, plasma adenosine levels were measured in those who ceased having hot flushes. Plasma adenosine levels were also measured in 9 perimenopausal women with few hot flushes (average age 47.2 \pm 2.4 (range: $42-51$ ) years old), 13 healthy women without hot flushes (average age 43.1 \pm 2.2 (range: $39-47$ ) years old) with serum E2 $\geq 50 \mathrm{pg} / \mathrm{ml}$ and FSH $<10 \mathrm{mIU} / \mathrm{ml}$, who were enrolled as the pre-menopausal group and in 10 healthy women who had not menstruated for more than 1 year (average age 52.1 \pm 1.3 (range: $49-54$ ) years old with serum E2 $<30 \mathrm{pg} / \mathrm{ml}$ and $\mathrm{FSH} \geq 40 \mathrm{mIU} / \mathrm{ml}$, who were 


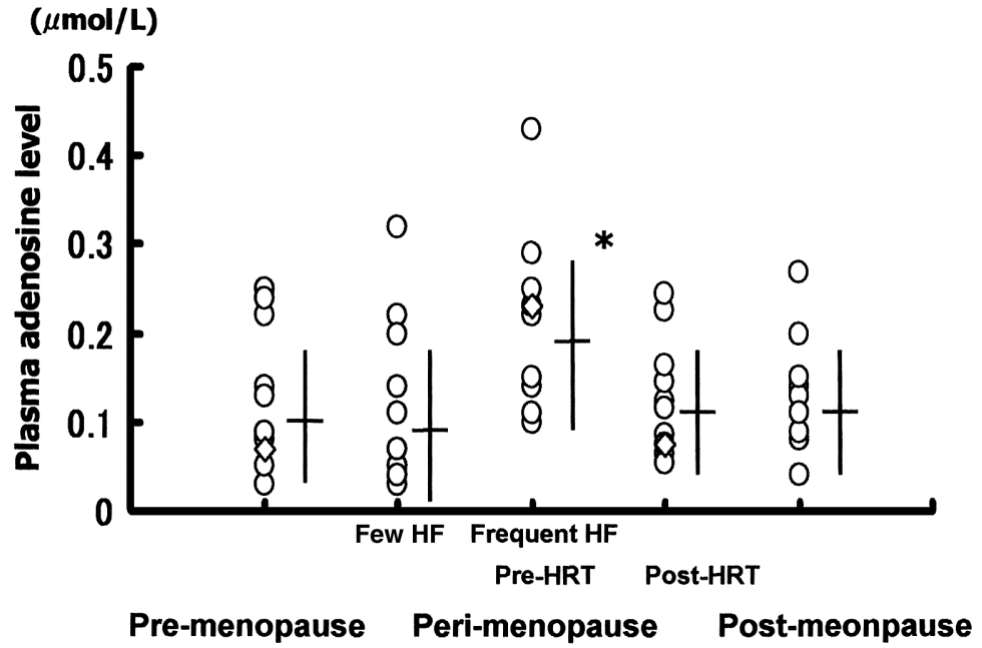

Fig 1. Plasma adenosine levels in pre-menopausal women, perimenopausal women with few hot flushes (HF) and frequent hot flushes before and 3-4 months after the start of hormone replacement therapy (HRT), and in postmenopausal women. ${ }^{*} \mathrm{p}<0.05$. enrolled as the postmenopausal group. The postmenopausal women were not complicated by hot flushes. Before blood samplings for measurement of adenosine, all patients were confirmed as having normal findings on electrocardiogram. In addition, there were no significant differences in body mass index among these 3 groups on Mann-Whitney U test (pre-menopause: $22.4 \pm 2.6$, peri-menopause with frequent hot flushes: $22.7 \pm 2.5$, peri-menopause with few hot flushes: 21.9 \pm 2.9 ,post-menopause: $23.1 \pm 3.0$ ).

For measurement of plasma adenosine levels, we took $3.0 \mathrm{ml}$ samples of blood from the left antecubital vein using a syringe containing an equal volume of ice-cold stop solution $(120 \mu \mathrm{mmol} / \mathrm{L}$ EHNA, $20 \mathrm{mmol} / \mathrm{L}$ dipyridamole, $60 \mathrm{mmol} / \mathrm{L} \mathrm{a}, \beta$-methylene adenosine-5' -diphosphate, and $4.2 \mathrm{mmol} / \mathrm{L} \mathrm{Na2EDTA}$ ). Samples were then stored as described previously 16 The mixtures were centrifuged at $1,500 \mathrm{~g}$ for $5 \mathrm{~min}$ at $4^{\circ} \mathrm{C}$. Plasma was transferred to an ultrafiltration cone (Amicon; Millipore Corp, Bedford, MA, USA) and deproteinized by centrifugation at 3,000 g for $1 \mathrm{~h}$ at $20^{\circ} \mathrm{C}$. Samples of ultrafiltrate were stored at $-70^{\circ} \mathrm{C}$ until analysis by high-performance liquid chromatography using the method previously reported 16,17 Briefly, $50 \mu$ l of ultrafiltrate was injected into a C18 column (Radial-Pac; Waters, Milford, MA, USA) and the absorbance of the eluate was monitored continuously at $254 \mathrm{~nm}$ for purine activity.

\section{Statistical Analysis}

Data are presented as mean \pm SD. Statistical comparisons were determined by one-way analysis of variance and then analyzed by Student's t-test or Mann-Whitney U test for multiple comparisons, as appropriate. A p-value $<0.05$ was considered significant.

\section{Results}

The average plasma adenosine level in the peri-menopausal group with frequent hot flushes was $0.20 \pm$ $0.09 \mu \mathrm{mol} / \mathrm{L}$, which was significantly higher than in the pre-menopausal group $(0.12 \pm 0.07 \mu \mathrm{mol} / \mathrm{L}, \mathrm{p}<0.05)$, perimenopausal group with few hot flushes $(0.10 \pm 0.09 \mu \mathrm{mol} / \mathrm{L}$, $\mathrm{p}<0.05)$ or the postmenopausal group $(0.13 \pm 0.06 \mu \mathrm{mol} / \mathrm{L}$, $\mathrm{p}<0.05$ ) (Fig 1). After HRT, however, the adenosine level $(0.13 \pm 0.06 \mu \mathrm{mol} / \mathrm{L})$ was not measurably different from those in the other 3 groups.

In this study, there was no correlation between plasma adenosine and serum E2 levels in the 4 groups.

\section{Discussion}

In this study, a significant increase in the plasma adenosine level was observed in peri-menopausal women who had frequent hot flushes compared with that in healthy women of a similar age with no or few hot flushes. HRT improved the symptoms and decreased the adenosine level to that found in healthy women of a similar age. In postmenopausal women without hot flushes, the plasma adenosine concentration was similar to that in pre-menopausal women, although the E2 levels were lower. In addition, there was no correlation between the plasma adenosine and serum E2 levels. These results are consistent with the concept that estrogen has no effect on adenosine in postmenopausal women.14,15 Although plasma adenosine decreased following HRT in the peri-menopausal women, the current results suggest that the increased plasma adenosine in climacteric women is not associated with decreased estrogen but with the symptom of hot flushes.

Adenosine is known to be cardioprotective via adenosine receptors 18 : (1) attenuation of the release of catecholamine, $\beta$-adrenoreceptor-mediated myocardial hypercontraction, and $\mathrm{Ca}^{2+}$ overload via A1 receptors; and (2) increased coronary blood flow, and inhibition of platelet and leukocyte activation via $\mathrm{A} 2$ receptors. The secretion of catecholamines from chromaffin cells is inhibited in part by adenosine 19 which also interferes with the release of norepinephrine from peripheral nerves and its actions there. In patients with chronic heart failure ${ }^{9,10}$ and pre-eclampsia ${ }^{20}$ adenosine has been supposed to contribute to negative feed-back mechanisms against the progressive loop between norepinephrine and systemic (micro-) circulatory disturbance. In this study, unfortunately, we did not examine the norepinephrine levels in patients with and without hot flushes. In perimenopausal women, however, the elevated plasma adenosine levels may be a physiological feed-back inhibitor that protects the maternal circulation from the vasoconstrictive effect of catecholamines and hence may advance the vasodilatory symptom of 'hot flushes'.

Despite the high prevalence of the phenomenon, the etiology of hot flushes, which are one of the most common complaints of peri-menopausal women, is still not completely understood, though a hypothesized central mechanism 
involving norepinephrine and luteinizing hormone-releasing hormone secretion is widely accepted?,21 In earlier studies using rats, the absence of sex steroids led to decreased reactivity to norepinephrine in peripheral small arteries contributing to the development of hot flushes, and estradiol replacement restored the impaired responsiveness of the vessels ${ }^{21,22}$ In addition, core body temperature elevations preceding menopausal hot flushes have been observed to be associated with a central noradrenagic mechanism in humans 23 Thus, increased plasma adenosine, although tending to counter this aspect of the process of 'hot flushes', is not able to completely compensate for it. In peri-menopausal women with frequent hot flushes, therefore, HRT both decreases the number of hot flushes and decreases the level of adenosine as a partial inhibitor of hot flushes.

In this study, the plasma adenosine level in postmenopausal women was not increased although their serum E2 levels were low, which is consistent with the concept that estrogen has no effect on adenosine in postmenopausal women! ${ }^{14,15}$ Moreover, HRT status has not shown any association with improvement in coronary circulation in postmenopausal women ${ }^{14}$ The postmenopausal state has been reported to be associated with a greater abnormality in endothelial function at the level of the microcirculation ${ }^{14}$ In addition, a hypothesis that other factors, such as age, may contribute more to endothelial dysfunction than hormone status has been discussed in relation to postmenopausal women. The net result may indicate a diminished or lost adenosine response despite continued circulatory dysfunction. The loss of adenosine responses indicates important limits to adenosine's protective action? 4

Overall, plasma adenosine levels in peri-menopausal women with frequent hot flushes were higher than those in pre- and postmenopausal women. Both the adenosine and the incidence of hot flushes were improved by HRT, but further study is needed to clarify the relationship between hot flushes and adenosine.

\section{References}

1. Matthews KA, Meillahn EN, Kuller LH, Kelsey SF, Caggiula AW, Wing RR. Menopause and risk factors for coronary heart disease. $N$ Engl J Med 1989; 321: 641-646.

2. Rosano GMC, Sarrel PM, Poole-Wilson PA, Collins P. Beneficial effect of oestrogen on exercise-induced myocardial ischemia in women with coronary artery disease. Lancet 1993; 342: 133-136.

3. Studee DW, Wilson KA, Pipili E, Croker AD. Physiological aspects of menopausal hot flush. BMJ 1978; 2: 79-80.

4. Lindheim SK, Legro KS, Bernstein L, Stanczyk FZ, Vijod MA, Presser SC, et al. Behavioral stress responses in premenopausal and postmenopausal women and the effects of estrogen. Am J Obstet Gynecol 1992; 167: 1831-1836.

5. Del Rio G, Menozzi R, Zizzo G, Avogaro A, Marrama P, Velardo A. Increased cardiovascular response to caffeine in perimenopausal women before and during estrogen therapy. Eur J Endocrinol 1996; 135: $598-603$.
6. Komesaroff PA, Esler MD, Sudhir K. Estrogen supplementation attenuates glucocorticoid and catecholamine responses to mental stress in perimenopausal women. J Clin Endocrinol Metab 1999; 84: $606-610$.

7. Genazzari AR, Gambacciani M, Simoncini T, Schneider HPG. 'Controversial issues in climacteric medicine' series 3rd Pisa Workshop 'HRT in climacteric and aging brain': Under the Auspices of the International Meopause Society, Pisa, Italy, 15-18 March 2003. Maturitas 2003; 46: 7-26.

8. Ohisaro JJ. Regulatory functions of adenosine. Med Biol 1987; 65: $181-191$.

9. Funaya H, Kitakaze M, Nobe K, Minamino T, Komamura K, Hori M. Plasma adenosine levels increase in patients with chronic heart failure. Circulation 1977; 95: 1363-1365.

10. Kitakaze M, Minamino T, Node K, Koretsune Y, Komamura K, Funaya $\mathrm{H}$, et al. Elevation of plasma adenosine levels may attenuate the severity of chronic heart failure. Cardiovasc Drugs Ther 1998; 12: 307-309.

11. Kitakaze M, Minamino T, Node K, Takashoma S, Funaya H, Kuzuya $\mathrm{T}$, et al. Adenosine and cardioprotection in the diseased heart. Jpn Circ J 1999; 63: 231-243.

12. Asakura M, Kitakaze M, Sakata Y, Asanuma H, Sanada S, Kim J, et al. Adenosine-induces cardiac gene expression of ischemic murine hearts revealed by cDNA array hybridization. Circ J 2002; 66: $93-$ 96.

13. Lim SY, Bae EH, Jeong MH, Kang DG, Lee YS, Kim KH, et al. Effect of combined intracoronary adenosine and nicorandil on noflow phenomenon during percutaneous coronary intervention. Circ J 2004; 68: $928-932$.

14. Halligan SC, Murtagh B, Lennon RJ, Pumper GM, Mathew V, Higano ST, et al. Effect of long-term hormone replacement therapy on coronary endothelial function in postmenopausal women. Mayo Clin Proc 2004; 79: 1514-1520.

15. Peterson LR, Eyster D, Davila-Roman VG, Stephens AL, Schechtman $\mathrm{KB}$, Herrero P, et al. Short-term oral estrogen replacement therapy does not augment endothelium-independent myocardial perfusion in postmenopausal women. Am Heart J 2001; 142: 641-647.

16. Yoneyama Y, Suzuki S, Sawa R, Yoneyama K, Power GG, Araki T. Relation between adenosine and T-helper 1/T-helper 2 imbalance in women with preeclampsia. Obstet Gynecol 2002; 99: 641-646.

17. Suzuki S, Power GG. Role of adenosine in regulation of brain temperature in fetal sheep. Am J Obstet Gynecol 1999; 181: 681-687.

18. Hori M, Kitakaze M. Adenosine, the heart and coronary circulation. Hypertension 1991; 18: 565-574.

19. Manyonda IT, Slater DM, Fenski C, Hole D, Choy MY, Wilson C. A role for noradrenaline in pre-eclampsia: Towards a uniflying hypothesis for the pathophysiology. Br J Obstet Gynaecol 1998; 105: 641 648.

20. Yoneyama Y, Suzuki S, Sawa R, Yoneyama K, Power GG, Araki T. Increased plasma adenosine concentrations and the severity of preeclampsia. Obstet Gynecol 2002; 100: 1266-1270.

21. Acs N, Vajo Z, Demendi C, Nadasy G, Monos E, Szekacs B. Estrogen improves impaired musculocutaneous vascular adrenergic reactivity in pharmacologically ovariectomized rats: A potential peripheral mechanism for hot flashes. Gynecol Endocrinol 2001; 15: $68-73$.

22. Acs N, Szekacs B, Nadasy GL, Varbiro S, Kakucs R, Monos E. The effect of ovariectomy and oestrogen replacement on small artery biomechanics in the rat. Br J Obstet Gynaecol 1999; 106: 148-154.

23. Freedman RR. Biochemical, metabolic, and vascular mechanisms in menopausal hot flashes. Fertil Steril 1998; 70: 332-337.

24. Kubonoya K, Power GG. Plasma adenosine responses during repeated episodes of umbilical cord occlusion. Am J Obstet Gynecol 1997; 177: 395-401. 